\title{
Hospital admission rates and the prevalence of asthma symptoms in 20 local authority districts
}

\author{
P G J Burney, A O Papacosta, C H Withey, J R T Colley, W W Holland
}

\begin{abstract}
Representative samples of 20-44 year old men living in 20 local authority districts in England were surveyed in 1986 by postal questionnaire and asked about symptoms associated with asthma and treatment for asthma. Regional health authorities provided information on all hospital discharges of men of the same age living in the same districts. Specific information was also provided on discharges where the primary cause of admission was for asthma. Admission rates for asthma were related to the prevalence of night time breathlessness and independently to the all cause admission rate for men of the same age. Admission rates were not significantly related to prescription rates of either

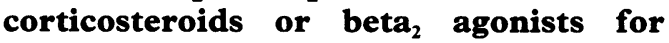
symptomatic men. This lack of association is hard to interpret without further information on variation in the severity of disease. These data show that admission rates for asthma are not dictated solely by health service characteristics, such as availability of beds or the "style" of the physician, but also reflect need. More research is required on how best to reduce the local prevalence and severity of asthma.
\end{abstract}

Hospital admission rates for children with asthma in England and Wales have increased considerably over the last two decades, ${ }^{1-4}$ an increase that could be largely accounted for by increases in the prevalence of asthma. ${ }^{56}$ Admissions for asthma have also increased in other countries, ${ }^{7}$ including the United States ${ }^{8}$ and New Zealand, ${ }^{9}$ and asthma is now one of the most common causes of admission to hospital among children in Western countries. The increase in admission to hospital is greatest in those born more recently and has therefore been less pronounced in the older age groups so far. ${ }^{3}$ Although the increase in hospital admissions has been frequently commented on, less is known about the distribution of admissions for asthma between different areas.

Variation in rates of hospital admission between areas is believed to be due partly to differences in need but far more to factors affecting access to hospital care, including the number of available beds and the practice style of the physicians who determine admission. ${ }^{10}$ There is little empirical evidence, however, to show how far prevalence of disease accounts for differences in use of services, though McPherson et al showed an association between cholecystectomy rates and the prevalence of gall stones at necropsy in nine British towns. ${ }^{11}$

There is concern at the increasing admission of people with asthma to hospital and the implications of this for the costs of the health service. This in turn raises the questions of why admission rates vary and how they could be controlled. The present study is an assessment of admission rates for asthma for 20-44 year old men living in 20 local authority districts in relation to the prevalence and management of asthma assessed by questionnaire in the same local authority districts.

\section{Methods}

THE POPULATION SAMPLES

A sample of local authority districts in England was selected according to their standardised mortality ratios for asthma in 20-64 year old men. The method of sampling was intended to maximise the variation in underlying mortality rates in the sample. Local authority districts with the highest asthma mortality and those with no deaths from asthma in the previous 10 years were selected. Because some districts had small populations, the lack of any deaths from asthma even in 10 years was not a reliable indication of a low risk of death from asthma. For this reason and because there were more local authority districts than were needed with no deaths from asthma, those local authority districts with no deaths but the highest expected number of deaths were selected. The last condition was set because the precision of the standardised mortality ratio increases with the expected number of deaths. Twenty four districts were originally selected but in some permission for the study was refused. Where this occurred others were substituted. In the end 34 districts were selected, in 21 of which approval was given. Inpatient data were not available for one of these districts and most analyses are therefore based on data from 20 districts. Permission was refused because of unwillingness to participate in a subsequent trial of lowering tar concentrations in cigarettes or because it was thought that other studies already being undertaken in the district would be prejudiced by a further large study in the area.

The electoral register in each district was used to sample the population. A random 
sample of men was selected from the register, a sampling ratio of $12 \cdot 5-50 \%$ being used. Of the 264024 men on the register, 129321 were estimated to be $20-44$ years old, and these were the subject of the current study. Subjects aged 18-19 on the electoral roll were excluded because they could not be identified separately in the routinely collected statistics, which report data only for the 15-19 year age group; those over 44 years were excluded because of the increasing problems of discriminating between asthma and other obstructive lung disease above this age. The survey was conducted from March to November 1986.

\section{QUESTIONNAIRE}

An early version of the bronchial symptoms questionnaire of the International Union Against Tuberculosis and Lung Disease ${ }^{1213}$ was used to elicit from the respondants symptoms that had occurred over the previous 12 months, together with information on smoking, age, and use of medication. Night time breathlessness was used as a proxy measure for asthma as it is a more specific symptom for bronchial hyperresponsiveness than wheeze ${ }^{13}$ and is not likely to be confounded with use of services, as seems to be the case with self reported asthma. ${ }^{14-16}$ Moreover, there is an a priori justification for using a marker of more severe disease when risk factors for admission to hospital are being investigated. All subjects were asked specifically about their use over the previous 12 months of inhaled beta ${ }_{2}$ agonists and inhaled corticosteroids, all of which were listed in the questionnaire by both their trade names and their proper names. In addition, subjects were asked to list any other medicines, pills, or inhalers that they had used to help their chest or breathing in the previous 12 months.

The questionnaire was mailed to the men identified from the electoral rolls with a letter of explanation and a reply paid envelope. A reminder was mailed after three weeks and a further questionnaire was mailed three weeks later if no reply had been received.

\section{INPATIENT DATA}

Regional medical officers were asked to provide data from the Hospital Activity Analysis on discharges and deaths from hospitals in their regions. Information was requested for $20-44$ year old men resident in any of the 21 local authority districts surveyed who had been discharged in 1985 or 1986 . The information was requested for each year separately, by five year age groups, by the principal diagnoses of asthma (ICD 493) and all chronic obstructive lung disease (ICD 491-493, 496), and for all causes.

\section{ANALYSIS}

A standardised admission ratio for asthma was calculated from the observed number of admissions from each local authority district and the number that would have been expected if the age specific rates in all the local authority districts studied had applied. The prevalence of night time breathlessness was adjusted for age and smoking habits. The association between the asthma admission ratios and other independent variables were estimated by multiple regression. The standardised ratio was regressed against the prevalence of waking at night with breathlessness and the standardised admission ratio for all causes for those aged 20 44 years. The proportion of those with night time breathlessness who were not using inhaled corticosteroids or who were not using inhaled beta ${ }_{2}$ agonists were also included as covariates. The multiple regression was performed by using the program GLIM after weighting by the method suggested by Pocock et al. ${ }^{17}$ Stratification of the analysis by the initial sampling strata of high and low mortality districts made no substantial difference to the results and is not shown.

\section{Results}

\section{RESPONSE RATES}

The response to the questionnaire was $64 \%$ overall, and varied from $58 \%$ to $70 \%$ between local authority districts. Of those responding, 74006 were aged $20-44$ years and had complete data. This represents $57 \%$ of the sample that were estimated to be in this age group.

Information on discharges was sought from regional health authorities on all residents from the local authority districts surveyed. One regional health authority (North East Thames) was unable to provide information for the years in question, so information is lacking for Brentwood. Wessex provided only a $20 \%$ sample of discharges for 1985 and a $10 \%$ sample for 1986 . Yorkshire provided a $100 \%$ sample in 1986 but no information for 1985 and Trent provided a $100 \%$ sample for 1985 and a $50 \%$ sample for 1986. All other regions provided a $100 \%$ sample in both years. The missing data were allowed for in the analysis by reducing the population used to estimate the expected number of admissions in proportion to the reduction in the sample observed. The weighting of the regression therefore remained in proportion to the actual observations. An exception was made when residents were treated outside the region where they lived. If in this case the regional health authority concerned with treatment had taken only a sample of discharges for the Hospital Activity Analysis, these were multiplied to give the estimated numbers treated. The only local authority district where this was a substantial proportion of all admissions was Mendip, where people were more or less equally likely to be treated by Wessex and by the South Western Regional Health Authority. Discharges of Mendip residents from hospitals in Wessex were multiplied to estimate the true number of admissions for residents in this local authority district. The only other local authority district where more than $10 \%$ of patients were treated in a different regional health authority was Boothferry, where $11 \%$ of residents admitted to hospital were treated in Trent regional health authority; but there was only one observed admission for asthma in the sample. 
Table 1 Prevalence of symptoms among 20-44 year old men resident in 21 local authority districts of England

\begin{tabular}{|c|c|c|c|c|}
\hline \multirow[b]{2}{*}{$\begin{array}{l}\text { Local authority } \\
\text { district }^{\star}\end{array}$} & \multirow[b]{2}{*}{$\begin{array}{l}\text { Number in } \\
\text { sample }\end{array}$} & \multicolumn{3}{|c|}{ Percentage prevalence (previous 12 months) } \\
\hline & & Wheeze & $\begin{array}{l}\text { Night time } \\
\text { breathlessness }\end{array}$ & $\begin{array}{l}\text { Self reported } \\
\text { asthma }\end{array}$ \\
\hline Blaby & 2287 & $9 \cdot 9$ & $3 \cdot 0$ & 3.5 \\
\hline Bolsover & 1855 & $11 \cdot 3$ & $3 \cdot 4$ & $3 \cdot 0$ \\
\hline Bolton & 3312 & $11 \cdot 6$ & 3.7 & 2.5 \\
\hline Boothferry & 3093 & $9 \cdot 4$ & $2 \cdot 8$ & $2 \cdot 3$ \\
\hline Bournemouth & 2772 & $11 \cdot 6$ & $4 \cdot 8$ & 4.9 \\
\hline Brentwood & 1917 & $10 \cdot 6$ & 3.6 & $3 \cdot 3$ \\
\hline Chester le Street & 2357 & $11 \cdot 8$ & $4 \cdot 0$ & $3 \cdot 7$ \\
\hline Erewash & 3038 & $12 \cdot 0$ & $3 \cdot 4$ & $3 \cdot 2$ \\
\hline Greenwich & 4389 & $12 \cdot 2$ & 3.9 & $3 \cdot \overline{3}$ \\
\hline Hambleton & 1620 & $8 \cdot 8$ & $3 \cdot 3$ & 3.6 \\
\hline Hammersmith and Fulham & 7010 & $12 \cdot 4$ & $4 \cdot 3$ & $4 \cdot 4$ \\
\hline High Peak & 2229 & $11 \cdot 9$ & $3 \cdot 4$ & $3 \cdot 5$ \\
\hline Huntingdon & 3070 & $10 \cdot 7$ & $4 \cdot 1$ & $4 \cdot 1$ \\
\hline Mendip & 2568 & $11 \cdot 8$ & $3 \cdot 2$ & $3 \cdot 3$ \\
\hline North Warwickshire & 2900 & $11 \cdot 0$ & $3 \cdot 4$ & 2.9 \\
\hline Nuneaton and Bedworth & 2970 & 11.5 & $3 \cdot 8$ & $2 \cdot 8$ \\
\hline Salisbury & 2711 & $10 \cdot 8$ & $4 \cdot 0$ & $4 \cdot 1$ \\
\hline South Tyneside & 8628 & 11.9 & 3.9 & 2.6 \\
\hline St Helens & 6322 & $13 \cdot 3$ & 3.9 & $3 \cdot 1$ \\
\hline Torridge & 2437 & $11 \cdot 3$ & $3 \cdot 8$ & 3.6 \\
\hline Wandsworth & 6521 & $12 \cdot 6$ & $4 \cdot 4$ & $4 \cdot 3$ \\
\hline
\end{tabular}

^Hospital Activity Analysis data not available for North East Thames Regional Health Authority.
Table 3 Proportion of men aged 20-44 years reporting waking at night with breathlessness who had not used specific inhalers in the previous 12 months

\begin{tabular}{lll}
\hline $\begin{array}{l}\text { Local authority } \\
\text { district }\end{array}$ & $\begin{array}{l}\text { Not having } \\
\text { beta }_{2} \\
\text { agonists }\end{array}$ & $\begin{array}{l}\text { Not having } \\
\text { steroids }\end{array}$ \\
\hline Blaby & $40 \cdot 6$ & $77 \cdot 6$ \\
Bolsover & $52 \cdot 9$ & $79 \cdot 0$ \\
Bolton & $48 \cdot 0$ & $79 \cdot 4$ \\
Boothferry & $48 \cdot 7$ & $81 \cdot 3$ \\
Bournemouth & $35 \cdot 1$ & $77 \cdot 6$ \\
Brentwood & $40 \cdot 5$ & $80 \cdot 3$ \\
Chester le Street & $42 \cdot 6$ & $74 \cdot 6$ \\
Erewash & $41 \cdot 6$ & $79 \cdot 2$ \\
Greenwich & $38 \cdot 0$ & $80 \cdot 7$ \\
Hambleton & $37 \cdot 6$ & $75 \cdot 9$ \\
Hammersmith and Fulham & $39 \cdot 5$ & $77 \cdot 5$ \\
High Peak & $42 \cdot 4$ & $71 \cdot 9$ \\
Huntingdon & $28 \cdot 8$ & $67 \cdot 2$ \\
Mendip & $44 \cdot 5$ & $89 \cdot 6$ \\
North Warwickshire & $37 \cdot 3$ & $80 \cdot 5$ \\
Nuneaton and Bedworth & $46 \cdot 0$ & $77 \cdot 3$ \\
Salisbury & $34 \cdot 4$ & $77 \cdot 4$ \\
South Tyneside & $47 \cdot 6$ & $78 \cdot 1$ \\
St Helens & $47 \cdot 9$ & $80 \cdot 3$ \\
Torridge & $41 \cdot 1$ & $84 \cdot 5$ \\
Wandsworth & $36 \cdot 6$ & $78 \cdot 9$ \\
\hline & & \\
\hline & & \\
\hline
\end{tabular}

QUESTIONNAIRE FINDINGS

The prevalence of self reported symptoms and diagnosis of asthma in the 21 local authority districts for 20-44 year old men is given in table 1. The prevalence of self reported wheeze varied from $8.8 \%$ in Hambleton (North Yorkshire) to $13.3 \%$ in St Helens (Merseyside). The prevalence of night time breathlessness varied from $2 \cdot 8 \%$ in Boothferry (Humberside) to $4.8 \%$ in Bournemouth (Dorset); and the prevalence of subjects saying that they had had asthma in the previous 12 months varied from $2.3 \%$ in Boothferry to $4.9 \%$ in Bournemouth.

The use of different drugs for asthma for the population as a whole and for those with night time breathlessness is shown in table 2 . As expected, the most commonly used medications were inhaled beta ${ }_{2}$ agonists and inhaled corticosteroids, though less than half of those with night time breathlessness were using beta agonists and only $15 \%$ inhaled corticosteroids. The proportion of those with night time breathlessness who had not used a beta ${ }_{2}$ agonist or corticosteroid inhaler in each local authority

Table 2 Number (\%) of men aged 20-44 years who had taken specific asthma medication in the previous 12 months

\begin{tabular}{|c|c|c|}
\hline \multirow[b]{2}{*}{ Medication } & \multicolumn{2}{|c|}{$\%$ taking the medication } \\
\hline & $\begin{array}{l}\text { In total } \\
\text { population }\end{array}$ & $\begin{array}{l}\text { Those with } \\
\text { night time } \\
\text { breathlessness }\end{array}$ \\
\hline $\begin{array}{l}\text { Inhaled beta }{ }_{2} \text { agonist } \\
\text { Inhaled corticosteroid }\end{array}$ & $\begin{array}{l}(\mathrm{n}=74006) \\
3 \cdot 65 \\
1 \cdot 16\end{array}$ & $\begin{array}{l}(n=3108) \\
44 \cdot 8 \\
15 \cdot 1\end{array}$ \\
\hline $\begin{array}{l}\text { Other asthma prophylactic } \\
\text { drugs } \\
\text { Oral beta }{ }_{2} \text { agonists } \\
\text { Theophyllines } \\
\text { Oral corticosteroids } \\
\text { Non-specific adrenergic } \\
\text { drugs }\end{array}$ & $\begin{array}{l}0.56 \\
0.43 \\
0.35 \\
0.17 \\
0.08\end{array}$ & $\begin{array}{l}7 \cdot 18 \\
4 \cdot 95 \\
5 \cdot 47 \\
2 \cdot 45\end{array}$ \\
\hline
\end{tabular}

$\star$ For breathing problems only. district in the 12 months before the questionnaire is shown in table 3. Huntingdon (Cambridgeshire) had the lowest proportion of men with symptoms who were not having treatment with each of the drugs. The highest proportion not treated by corticosteroids was in Mendip (Somerset) and the highest proportion not treated by a beta ${ }_{2}$ agonist was in Bolsover (Derbyshire).

\section{HOSPITAL DISCHARGE RATES}

The observed and expected discharges for asthma in each local authority district together with the ratio (standardised discharge ratio) are shown in table 4 . The standardised discharge ratios from all causes for men aged $20-44$ are also given. The wide variation in standardised discharge ratios for asthma reflects in part the small number of discharges for some local authority districts.

Table 5 gives the results from a multiple regression of the standardised discharge ratio for asthma against the prevalence of night time breathlessness, the all cause discharge rate, and the proportion of those with night time breathlessness who were untreated with inhaled corticosteroids. The standardised discharge ratio for asthma was associated with the prevalence of night time breathlessness $(p<0.02)$ but the association with the all cause admission rate failed to reach conventional levels of significance $(0.10>p>0.05)$. There was a positive association with the proportion of men with night time breathlessness who were not being treated with an inhaled corticosteroid, but this was not significant either $(p>0 \cdot 20)$. When the proportion of men not taking corticosteroids is dropped from the model significant associations are seen with both the prevalence of night time breathlessness $(p<$ 0.02 ) and the standardised all cause admission rate $(\mathrm{p}<0.05)$. 
Table 4 Observed and expected discharges with asthma and standardised asthma discharge ratio and discharges from all causes for 20-44 year old male residents by local authority district

\begin{tabular}{|c|c|c|c|c|}
\hline \multirow{2}{*}{$\begin{array}{l}\text { Local authority } \\
\text { district }^{\star}\end{array}$} & \multicolumn{2}{|c|}{ Discharges with asthma $+(1985-6)$} & \multirow{2}{*}{$\begin{array}{l}\text { Standardised } \\
\text { asthma } \\
\text { discharge ratio }\end{array}$} & \multirow{2}{*}{$\begin{array}{l}\text { Standardised } \\
\text { discharge ratio } \\
\text { (all causes) }\end{array}$} \\
\hline & Observed & Expected & & \\
\hline Blaby & 1 & $12 \cdot 8$ & 14 & 67 \\
\hline Bolsover & 2 & $10 \cdot 6$ & 19 & 89 \\
\hline Bolton & 67 & $54 \cdot 5$ & 123 & 116 \\
\hline Boothferry & 1 & $6 \cdot 3$ & 16 & 102 \\
\hline Bournemouth & 3 & 3.9 & 77 & 128 \\
\hline Chester-le-Street & 4 & $11 \cdot 4$ & 35 & 110 \\
\hline Erewash & 1 & $16 \cdot 7$ & 20 & 72 \\
\hline Greenwich & 83 & $46 \cdot 5$ & 178 & 110 \\
\hline Hambleton & 4 & $7 \cdot 8$ & 51 & 115 \\
\hline Hammersmith and Fulham & 65 & $36 \cdot 0$ & 181 & 94 \\
\hline High Peak & 10 & $17 \cdot 2$ & 58 & 106 \\
\hline Huntingdon & 21 & $33 \cdot 0$ & 64 & 60 \\
\hline Mendip & 31 & $18 \cdot 2$ & 170 & 109 \\
\hline North Warwickshire & 7 & $12 \cdot 7$ & 55 & 91 \\
\hline Nuneaton and Bedworth & 18 & $23 \cdot 7$ & 76 & 101 \\
\hline Salisbury & 4 & $3 \cdot 2$ & 125 & 105 \\
\hline South Tyneside & 33 & $31 \cdot 4$ & 105 & 123 \\
\hline St Helens & 31 & $38 \cdot 7$ & 80 & 127 \\
\hline Torridge & 12 & $9 \cdot 2$ & 130 & 95 \\
\hline Wandsworth & 57 & 61.5 & 93 & 83 \\
\hline
\end{tabular}

*Hospital Activity Analysis data not available for North East Thames Regional Health Authority.

†Data not all complete for the whole period: see under "Methods."

\section{Discussion}

This study suggests that the use of hospitals by asthmatic patients may be explained in part by the prevalence of symptoms of moderate to severe asthma, and to a smaller extent by the overall use of hospitals by the population.

Although we may reasonably suppose that asthma prevalence rates might be important in determining hospital use, this has rarely been studied directly. In this study the prevalence of night time breathlessness accounted for about $22 \%$ of the variation in admissions for asthma (26\% in the model that includes use of corticosteroids). The use of symptoms to define asthma is to be preferred because of the recorded association between self reported asthma and specific treatment of the condition. ${ }^{14-16}$ Use of self reports to define asthma in surveys will therefore lead to a spuriously good association between morbidity and appropriate treatment. The symptom of nocturnal dyspnoea was preferred to that of wheezing because wheeze is a relatively non-specific symptom of bronchial hyperresponsiveness ${ }^{1213}$ and would therefore lead to greater misclassification. There is furthermore an a priori reason to select a relatively severe symptom for assessment of the risk of admission to hospital. As symptoms might be affected by smoking and age, indepen- dently of asthma, the prevalence of breathlessness was adjusted for these two variables. This had little effect on the analysis, as might be expected in this relatively young age group.

As most admissions for asthma occur as emergencies, many patients referring themselves directly to the casualty department, ${ }^{1}$ the prevalence of severe disease might be expected to have a prominent role in determining admission rates. In many conditions the general practitioner may act more easily as gatekeeper, or the hospital doctor may apply more rigid control over the selection and timing of admissions, though this goes against many current assumptions concerning variation in hospital use. Wennberg ${ }^{18}$ has argued that where admission rates are determined by incidence or prevalence these rates are generally relatively constant from place to place, and that large variations in admission rates generally reflect differences in physicians' beliefs and practices. Although this may be largely true, it cannot be assumed to be the case in the absence of any evidence on variations in the prevalence of morbidity.

A response rate of around $60 \%$ makes any estimate of prevalence unreliable and the figures quoted in tables 1-3 should be treated with caution. The prevalence of the symptoms

Table 5 Multiple regression of the logarithm of the standardised discharge ratio for asthma against the all cause discharge ratio, the prevalence of night time breathlessness, and the percentage of all men with night time breathlessness not having inhaled corticosteroids, showing the partial regression coefficients together with their standard errors and $95 \%$ confidence intervals (results shown with and without adjustment for the use of inhaled steroids)

\begin{tabular}{|c|c|c|c|c|}
\hline & $\begin{array}{l}\text { Partial regression } \\
\text { coefficient }\end{array}$ & $\begin{array}{l}\text { Standard } \\
\text { error }\end{array}$ & $\begin{array}{l}95 \% \text { confidence } \\
\text { interval }\end{array}$ & $\begin{array}{l}\% \text { of variance } \\
\text { explained }\end{array}$ \\
\hline $\begin{array}{l}\text { All cause admission rate } \\
\% \text { prevalence of night time breathlessness } \\
\% \text { of those with night time breathlessness not having }\end{array}$ & $\begin{array}{l}0.0188 \\
1.031^{\star \star}\end{array}$ & $\begin{array}{l}0.0098 \\
0.3584\end{array}$ & $\begin{array}{r}-0.002 \text { to } 0.040 \\
0.268 \text { to } 1.794\end{array}$ & $\begin{array}{l}11 \cdot 4 \\
25 \cdot 6\end{array}$ \\
\hline inhaled steroids & 4.950 & $4 \cdot 274$ & $-4 \cdot 161$ to $14 \cdot 01$ & $4 \cdot 2$ \\
\hline $\begin{array}{l}\text { Same regression with the effects of inhaled steroids ignored } \\
\text { All cause admission rate } \\
\text { Prevalence of night time breathlessness }\end{array}$ & $\begin{array}{l}0.0228^{\star} \\
0.8885^{\star \star}\end{array}$ & $\begin{array}{l}0.0093 \\
0.3413\end{array}$ & $\begin{array}{l}0.003 \text { to } 0.042 \\
0.168 \text { to } 1.609\end{array}$ & $\begin{array}{l}19.1 \\
21.5\end{array}$ \\
\hline
\end{tabular}

${ }^{\star} \mathrm{p}<0.005 ; \star \star \mathrm{p}<0.02$ 
and diagnosis of asthma are within the range quoted by other authors. ${ }^{19}$ Although the overall prevalence of men taking medication appears to be high, it is still considerably lower than the figures quoted for primary school children. Hill et $a l^{20}$ estimated that $6.6 \%$ of primary school children in Nottingham were receiving treatment for asthma and that $5.5 \%$ were receiving beta ${ }_{2}$ agonists. Although estimates of prevalence are unreliable because of the low response rate, the differences in response rate between areas are unlikely to have created the associations reported in this paper. We found no association between discharge rates and response rates, suggesting that systematic confounding by response rate does not explain the associations reported here.

The variation in admission rate for all causes in this age group accounted for about $19 \%$ of the variation in the asthma discharge rate $(11 \%$ in the model that includes use of corticosteroids). The independent association with the all cause admission rate for the same age group suggests that there is a factor common to all conditions that influences discharge rates. This may be a characteristic of the service, such as the availability of beds and staff, or of the local general practitioner services, or it may be a characteristic of the population. For instance, the population may be less easily cared for at home because of social circumstances, or may be more insistent in its demands for admission. In the United States wide variations in discharge rates for asthma and related conditions have also been noted. In a comparison of hospital use in New Haven and Boston, obstructive lung diseases were among the conditions with the most variable discharge rates, a variation that was related to overall provision of hospital resources, and ascribed to different styles of practice. ${ }^{21}$ On the other hand, a study in Maryland showed no association between admissions for asthma and the resources available, but showed instead admissions to be strongly associated with race and poverty. ${ }^{22}$ Both these associations were specific for admissions for asthma and both were strongly related to asthma prevalence in Maryland. ${ }^{23}$

The association between treatment with inhaled corticosteroids and admission rates did not reach significance $(p>0.20)$, and the estimated effect would suggest that current variations in the use of inhaled corticosteroids account for only $4 \%$ of the variation in admission rates. The questionnaire did not, however, provide the information needed to make a reliable judgement on whether the corticosteroids were being used appropriately. Moreover, this analysis takes no account of variation in severity of disease other than by selecting a relatively severe symptom to define the prevalence of asthma. The sample of men with night time breathlessness will itself contain considerable variation in severity of disease, and use of inhaled corticosteroids may be a marker of the severity of the disease as well as of good treatment. The observation that use of corticosteroids appeared to be protective suggests that their role in preventing admission may have outweighed their importance as a marker of severity. In this case a fuller adjustment for "severity" of disease might have increased this apparent effect. If inhaled corticosteroids reduce admissions for asthma this is important in view of concern over the high cost of inhaled corticosteroids, and suggests the need for further research to determine the cost effectiveness of corticosteroids in managing asthma. A similar analysis of the use of inhaled beta $a_{2}$ agonists suggested that variation in their use accounted for less than $4 \%$ of the variation in admission rates. In this case the association between use of beta ${ }_{2}$ agonists and mortality was positive. The wide confidence intervals, however, and the considerations that apply to corticosteroids make this association difficult to interpret.

The variation in prevalence that gives rise to the variation in discharge rate has been given relatively little attention. In this study prevalence of nocturnal breathlessness accounts for over $20 \%$ of the variation in discharge rates. Reducing the prevalence might provide the most effective and efficient method of reducing admissions to hospital. So far little is known about the causes of geographical variation in the prevalence and severity of asthma, but these differences are likely to be environmental in origin and it is these variations that should be determined and controlled. Such a programme could lead to a reduction in morbidity and both the use of drugs and hospital admission rates.

Our results strongly suggest that a substantial part of the variation in asthma admission rates is due to variation in the underlying prevalence of the condition, and not to the local supply of services or physicians' style of practice. A further substantial part of the variation is related to the overall local admission rate for all causes, and this would be related either to supply of services or to physicians' style (though this would seem unlikely to be consistent over all specialties), to local needs of the population unrelated to prevalence of disease, such as poor social conditions, or to the local quality of general practitioner services. Although a further component of the variation in admission rates could be related to the use of medication, we were unable to detect such an effect.

We would like to thank Dr Fiona North, Mrs Joanna Terry, and Ms Beverley Fitzsimmons for their help in this survey; Ms Nicky Smith for secretarial support, and Social and Community Planning Research for undertaking the sampling and mailing. The study was funded by the Tobacco Products Research Trust.

1 Anderson HR, Bailey P, West S. Trends in hospital care of acute childhood asthma 1970-8: a regional study. BMJ 1980;281:1191-4.

2 Khot A, Burn R, Evans N, Lenney C, Lenney W. Seasonal variation and time trends in childhood asthma in England variation and time trends in childhood asth
and Wales 1975-81. BMJ 1984;289:235-8.

3 Alderson $M$. Trends in morbidity and mortality from asthma. Population Trends 1987;49:18-23.

4 Hill AM. Trends in paediatric medical admissions. BMJ 1989;298:1479-83.

5 Burr ML, Butland BK, King S, Vaughan-Williams E. Changes in asthma prevalence in two surveys 15 years Changes in asthma prevalence in two
apart. Arch Dis Child 1989;64:1452-6.

6 Burney PGJ, Chinn S, Rona R. Has asthma prevalence increased in children? Evidence from the National Study of Health and Growth 1973-86. BMJ 1990;300:1306-10. 
7 Mitchell EA. International trends in hospital admissions rates for asthma. Arch Dis Child 1985;60:376-8.

8 Halfon N, Newachek PW. Trends in the hospitalisation for acute childhood asthma, 1970-84. Am J Public Health 1986;76:1308-11.

9 Mitchell EA, Cutler DR. Paediatric admissions to Auckland Hospital for asthma from 1970-80. N Z Med J 1984;97: $67-70$

10 Morgan M, Mays N, Holland WW. Can hospital use be a measure of need for health care? J Epidemiol Community Health 1987;41:269-74.

11 McPherson K, Strong PM, Jones L, Britton BJ. Do cholecystectomy rates correlate with geographic variations in the prevalence of gallstones? I Epidemiol Commun ity Health 1985;39:179-82.

12 Burney PGJ, Chinn S. Developing a new questionnaire fo measuring the prevalence and distribution of asthm Chest 1987;91:79-83S

13 Burney PGJ, Chinn S, Britton JR, Tattersfield AE, Papacosta AO. What symptoms predict the bronchial response to histamine? Evaluation in a community survey of the Bronchial Symptoms Questionnaire (1984) of the International Union against Tuberculosis and Lung Disease. Int J Epidemiol 1989;18:165-73.

14 Anderson HR, Cooper JS, Bailey PA, Palmer JC. Influence of morbidity, illness label and social, family and
Lancet 1981;ii:1030-2.

15 Speight ANP, Lee DA, Hey EN. Underdiagnosis and undertreatment of asthma in childhood. BMJ 1983; 286:1253-6

16 Littlejohns P, Ebrahim S, Anderson R. Treatment of adult asthma: is the diagnosis relevant? Thorax 1989;44: 797-802.

17 Pocock SJ, Cook DG, Beresford SAA. Regression of area mortality rates on explanatory variables: what weighting is appropriate? Applied Statistics 1981;30:286-90.

18 Wennberg J. Which rate is right? $N$ Engl J Med 1986; 314:310-1

19 Gregg I. Epidemiological aspects. In: Clark TJH, Godfrey S. Asthma. 2nd ed. London: Chapman and Hall, 1983: 242-84.

20 Hill RA, Williams J, Tattersfield AE, Britton JR. Asthma, wheezing, and school absence in primary schools. $B M$ 1989;299:898.

21 Wennberg JE, Freeman JL, Culp WJ. Are hospital services rationed in New Haven or over-utilised in Boston? Lancet 1987;i:1185-8.

22 Wissow LS, Gittlesohn AM, Szklo M, Starfield B, Mussman M. Poverty, race and hospitalization for childhood asthma. Am J Public Health 1988;78:777-82.

23 Mak $\mathrm{H}$, Johnston P, Abbey $\mathrm{H}$, Talamo RC. Prevalence of P. Abbey utilization of asthmatic children in an inner city. $J$ Allergy Clin Immunol 1982;70:367-72. 